Check for updates

Cite this: RSC Adv., 2017, 7, 54570

Received 7th October 2017

Accepted 22nd November 2017

DOI: 10.1039/c7ra11022g

rsc.li/rsc-advances

\title{
Ultraviolet-responsive self-assembled metallomicelles for photocontrollable catalysis of asymmetric sulfoxidation in water $\dagger$
}

\author{
Mengqiao Gao, Rong Tan, (D) * Pengbo Hao, Yaoyao Zhang, Jiang Deng \\ and Donghong Yin
}

Self-assembled metallomicelles with ultraviolet (UV)-controlled morphologies were constructed from a synthesized azobenzene-containing amphiphilic chiral salen $\mathrm{Ti}^{\mathrm{IV}}$ catalyst. The morphologies of the metallomicelles could be well adjusted by changing the UV irradiation time, and this was confirmed by TEM analyses. The UV-induced change in morphology potentially adjusted the catalyst concentration and/or accessibility in real-time, allowing photocontrollable catalysis of asymmetric sulfoxidation in water. UV-responsive catalytic activities with excellent selectivities were observed over the metallomicelles for a wide range of alkyl aryl sulfides. Moreover, a thermo-responsive NIPAAm block in the catalyst enables it to be easily recovered for steady reuse by thermo-controlled separation. This work constructed a photo-responsive metallomicellar system to carry out metallomicellar catalysis in a controllable way.

\section{Introduction}

Metallomicellar systems, which exhibit similar structural and kinetic properties to natural enzymes, have been extensively investigated as effective biomimetic systems for asymmetric catalysis in water. ${ }^{1}$ The ability to carry out metallomicellar catalysis in a controllable way has profound importance in chemical synthesis, and this area has garnered intense interest. The key to achieving this controllable catalysis was developing a metallomicellar system in which the concentration and/or accessibility of catalytic sites in reaction media could be adjusted in a controlled manner. ${ }^{2}$ Stimuli-responsive metallomicelles were thus developed to control catalytic reactions via external signals. ${ }^{3}$ The metallomicelles often undergo instantaneous morphological and/or architectural changes upon exposure to an external stimulus, consequently altering their catalytic properties. ${ }^{4}$ Lately, we have reported thermoresponsive metallomicelles for enantioselective sulfoxidation at room temperature in water by using a chiral salen $\mathrm{Ti}^{\mathrm{IV}}$ complex as the catalytic site and NIPAAm as the thermo-trigger. $^{3 c}$ The metallomicelles underwent reversible switching between self-assembly and precipitation in aqueous system in

Key Laboratory of Chemical Biology and Traditional Chinese Medicine Research, Ministry of Education, National \& Local Joint Engineering Laboratory for New Petro-chemical Materials and Fine Utilization of Resources, Hunan Normal University, Changsha 410081, P. R. China. E-mail: yiyangtanrong@126.com; Tel: $+86-731-8872576$

$\dagger$ Electronic supplementary information (ESI) available: Preparation and identity of the catalysts, NMR and HPLC analysis for the chiral sulfoxides. See DOI: $10.1039 / \mathrm{c} 7 \mathrm{ra11022g}$ response to local temperature. At room temperature which was its lower critical solution temperature (LCST), catalysts were amphiphilic and self-assembled to form metallomicelles, accelerating the aqueous sulfoxidation by "concentration effect". Upon heating above their LCST, they switched to hydrophobic compounds, and thus precipitated from aqueous system for facile recovery. The switchable behavior turned the enantioselective sulfoxidation on or off at will by adjusting local temperature. Nevertheless, in the metallomicellar catalysis, chemical processes were typically limited to a fixed rate and/or selectivity once the catalyst and reaction condition are chosen, control of catalytic activity as the reaction proceeds was difficult to achieve. Logically, if the morphology and/or architecture of the metallomicelles can be adjusted in real-time by external stimuli, controlled catalysis of asymmetric sulfoxidation should be realized.

Light irradiation, a green and sustainable energy which could be precisely manipulated in a clean environment without pollution to reaction system, was considered as an ideal external stimulus for controllable catalysis. A variety of lightresponsive moieties was introduced in catalysts to give the catalytic system response to light. ${ }^{2 a, 5}$ Among them, azobenzene has received much attention in recent years due to its wellknown reversible photoisomerization from trans- to cis-configuration. Amphiphilic catalysts containing azobenzene group often undergo conformational and electronic changes upon light irradiation. ${ }^{6}$ It offered an attractive alternative to modulate morphology and/or architecture of metallomicelles in real-time. With these points in mind, we decided to incorporate azobenzene as the hydrophobic block of amphiphilic chiral salen 
$\mathrm{Ti}^{\mathrm{IV}}$ catalyst to develop photo-controlled metallomicellar catalytic system of asymmetric sulfoxidation in water. We envisioned that in aqueous media, the azobenzene-containing amphiphilic catalyst should self-assemble through hydrophobic interaction and $\pi-\pi$ staking of azobenzene group, forming micelle having hydrophobic azobenzene core. Catalytically active Ti(salen) was grafted on azobenzene segment to ensure the effective shielding of catalytic sites in the hydrophobic compartment, mimetic of enzyme. The self-assembled metallomicelles would behave as biomimetic nanoreactor, accelerating asymmetric sulfoxidation in water. In particular, the salient feature of azobenzene, reversible structural changes in the photoisomerization (trans/cis), should be beneficial for temporal control of the metallomicelles morphology using light. This unique property allowed one to control the metallomicellar catalysis of aqueous asymmetric sulfoxidation by external light irradiation. Thermo-responsive NIPAAm, which underwent hydrophilic-to-hydrophobic transformation at its LCST, ${ }^{7}$ was selected as the "smart" hydrophilic block to control self-assembly and precipitation of Ti(salen)-containing metallomicelle in the aqueous system.

Herein, well-defined diblock copolymer of poly(NIPAAm-coazo) (NIPAAm, $N$-isopropylacrylamide; azo, azobenzene) was synthesized by copolymerizing NIPAAm with $N$-azo-acrylamide via atom transfer radical polymerization (ATRP). ${ }^{8}$ Covalently appending chiral salen $\mathrm{Ti}^{\mathrm{IV}}$ complex on the azobenzene block provided an amphiphilic chiral salen $\mathrm{Ti}^{\mathrm{IV}}$ catalyst responsive to temperature and UV irradiation. At the reaction temperature $\left(25{ }^{\circ} \mathrm{C}\right)$, the catalyst was amphiphilic and self-assembled into metallomicelles in water, accelerating the aqueous asymmetric sulfoxidation by "concentration effect". UV irradiation provoked the morphological change of metallomicelles, which thus controlled the metallomicellar catalysis of asymmetric sulfoxidation in water. After reaction, the catalyst became hydrophobic upon heating above its LCST, and precipitated from aqueous system for recovery. The activity switching was repeatable even after seven cycles.

\section{Results and discussion}

\section{Preparation of catalysts}

Stimuli-responsive metallomicellar catalysis, in which intrinsic activity could be finely modulated in real-time by external stimulus, was highly desirable in biomimetic catalysis., ${ }^{2,5 e}$ Light was attractive stimulus for this stimuli-responsive system, since it offered excellent temporal and spatial resolution, and could be precisely controlled with an appropriate source. The key to achieving the light-controlled catalysis was developing the metallomicelle whose morphology and/or architecture in reaction media could be instantaneously induced by light stimuli. $^{2 a, 5}$ Azobenzene with reversible $E / Z$ photoisomerization was an ideal photosensitive group for constructing the lightresponsive metallomicelle. ${ }^{6}$ With these points in mind, we decided to incorporate hydrophobic azobenzene into amphiphilic chiral salen $\mathrm{Ti}^{\mathrm{IV}}$ catalyst to fabricate a $\mathrm{Ti}($ salen)containing metallomicelle for photocontrollable catalysis of asymmetric sulfoxidation in water. PNIPAAm which underwent reversible switching between hydrophilicity and hydrophobicity at its LCST was incorporated as the "smart" hydrophilic block to ensure not only self-assembly of catalyst for metallomicellar catalysis, but also recovery of catalyst for efficient reuse in the aqueous system.

The synthesis of thermo/photo-responsive chiral salen $\mathrm{Ti}^{\mathrm{IV}}$ catalyst of $\mathbf{P N}_{427} \mathbf{A}_{10}-\mathbf{C}$ was illustrated in Scheme 1. First, welldefined diblock copolymer of poly(NIPAAm-co-azo) (denoted as $\left.\mathbf{P N}_{\mathbf{4 2} 7} \mathbf{A}_{\mathbf{1 0}}\right)$, featuring a terminated amino $\left(-\mathrm{NH}_{2}\right)$ group on azobenzene block, was prepared via ATRP by using $N, N$-azobi$\mathrm{s}$ (isobutyronitrile) (AIBN) as a radical initiator and 2-aminoethanethiol hydrochloride (AET) as the chain transfer agent. Successive $N$-alkylation of the terminal amino group $\left(-\mathrm{NH}_{2}\right)$ with benzyl chloride group $\left(-\mathrm{CH}_{2} \mathrm{Cl}\right)$ at the 5-position of an reported asymmetric chiral salen ligand (CL) of $(R, R)$ - $N$-(3,5-di-tert-butylsalicylidene)- $N^{\prime}$-[3-tert-butyl-5-chloromethylsalicylidene]-1,2-cyclohexane-diamine ${ }^{9}$ resulted in covalently appending chiral salen ligand on the hydrophobic segment of $\mathbf{P N}_{\mathbf{4 2} 7} \mathbf{A}_{\mathbf{1 0}}$, as shown in Scheme 1. The strategy ensured shielding of the catalytic motif in hydrophobic domain (protected by the hydrophilic corona) upon self-assembly in water, which was a salient feature of enzyme catalysis. The resultant $\mathbf{P N}_{\mathbf{4 2} 7} \mathbf{A}_{\mathbf{1 0}}$-modified chiral salen ligand was coordinated with $\mathrm{Ti}\left(\mathrm{O}^{\mathrm{i}} \mathrm{Pr}\right)_{4}$ and further treated with $\mathrm{H}_{2} \mathrm{O}$, giving $\mathbf{P N}_{\mathbf{4 2}} \mathbf{A}_{\mathbf{1 0}}$-modified chiral salen $\mathrm{Ti}^{\mathrm{IV}}$ complex. Excess $\mathrm{Ti}\left(\mathrm{O}^{\mathrm{i}} \mathrm{Pr}\right)$ was hydrolyzed into $\mathrm{TiO}_{2}$ and then was removed by filtration, affording the thermo/photo-responsive chiral salen $\mathrm{Ti}^{\mathrm{IV}}$ catalyst of $\mathbf{P N}_{\mathbf{4 2 7}} \mathbf{A}_{\mathbf{1 0}}-\mathbf{C}$ (where 427 and 10 represented the repeated units number of NIPAAm and azobenzene in copolymer, which were determined by ${ }^{1} \mathrm{H}$ NMR spectrum, as shown in $\left.\mathrm{ESI} \dagger\right)$.

Unlike traditional chiral $((R, R)$-salen $) \mathrm{Ti}^{\mathrm{IV}}\left(\mathrm{O}^{\mathrm{i}} \mathrm{pr}\right)_{2}$ complex $^{10}$ (denoted as neat complex, as shown in Chart 1) that was completely insoluble in water, the obtained $\mathbf{P N}_{\mathbf{4 2 7}} \mathbf{A}_{\mathbf{1 0}}$-C presented temperature-controlled water-solubility with the LCST of $26^{\circ} \mathrm{C}$. The LCST which was approximate to room temperature $\left(25^{\circ} \mathrm{C}\right)$ made $\mathbf{P N}_{\mathbf{4 2} 7} \mathbf{A}_{\mathbf{1 0}}$-C self-assemble at room temperature and separate also at mild temperature (slightly higher than room temperature) in the aqueous asymmetric sulfoxidation. Actually, to regulate the LCST close to room temperature, various rations of NIPAAm to azobenzene blocks have been modulated

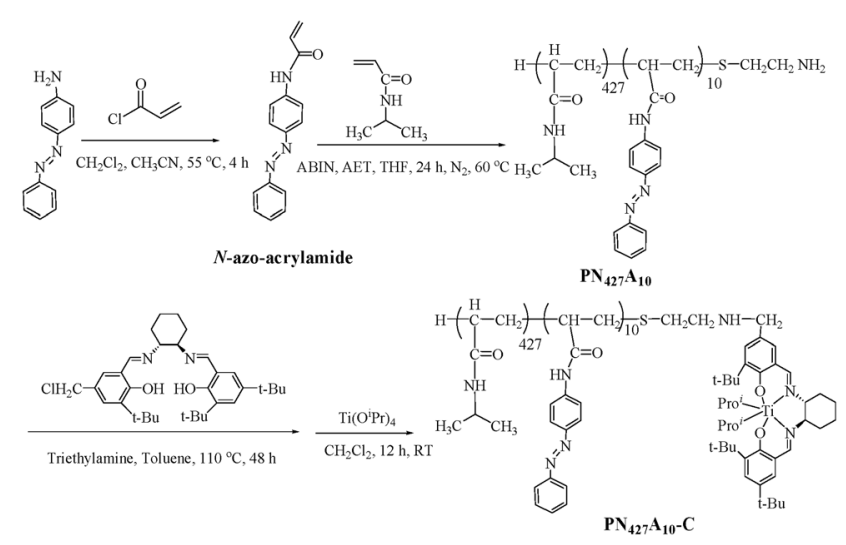

Scheme 1 Synthesis of $\mathrm{PN}_{427} \mathrm{~A}_{10}-\mathrm{C}$ 


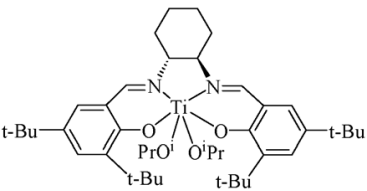

Chart 1 Structure of neat complex.

in the chiral salen $\mathrm{Ti}^{\mathrm{IV}}$-containing amphiphiles. The detail synthesis and identification of the controlled copolymers were available in the ESI. $\dagger$

\section{Characterization of samples}

LCST determination. Thermo-responsive behavior of $\mathbf{P N}_{\mathbf{4 2 7}} \mathbf{A}_{10}$-C was investigated by monitoring the optical transmittance of typical $\mathbf{P N}_{\mathbf{4 2}} \mathbf{A}_{\mathbf{1 0}}-\mathbf{C}$ solution at $440 \mathrm{~nm}$ using UV-vis spectrophotometry (Fig. 1). Obviously, $\mathbf{P N}_{\mathbf{4 2 7}} \mathbf{A}_{\mathbf{1 0}}$-C was well soluble in water, giving clear aqueous solutions at temperature below $26{ }^{\circ} \mathrm{C}$ (Fig. 1A), although neat complex was practically insoluble in water. When the local temperature was raised to $26^{\circ} \mathrm{C}$, the aqueous solution became turbid, and transmittance decreased dramatically (Fig. 1A). It suggested a hydrophobic state of $\mathbf{P N}_{\mathbf{4 2}} \mathbf{A}_{\mathbf{1 0}}-\mathbf{C}$ at this temperature range. Therefore, the LCST of $\mathbf{P N}_{427} \mathbf{A}_{10}$ - $\mathrm{C}$ was determined as $c a .26{ }^{\circ} \mathrm{C}$. We noticed that the temperature was much lower than LCST of pure PNIPAAm microgel $\left(32{ }^{\circ} \mathrm{C}\right)$. This difference confirmed the successful incorporation of hydrophobic azobenzene block and Ti(salen) unit into PNIPAAm, which changed the hydrophilicity-hydrophobicity balance in copolymer, and thus lower the LCST. ${ }^{11}$ It was the combined hydrophobic block that made $\mathbf{P N}_{\mathbf{4 2 7}} \mathbf{A}_{\mathbf{1 0}}$-C amphiphilic and ensured the self-assembly of the $\mathbf{P N}_{\mathbf{4 2 7}} \mathbf{A}_{10}-\mathbf{C}$ in water. By continuous cooling to below $26^{\circ} \mathrm{C}$, the $\mathbf{P N}_{427} \mathbf{A}_{\mathbf{1 0}}-\mathbf{C}$ aqueous solution reverted to the initial clear state, suggesting the returned amphiphilic state of $\mathbf{P N}_{\mathbf{4 2 7}} \mathbf{A}_{\mathbf{1 0}}-\mathbf{C}$. Significantly, the water-solubility switch could be reversibly repeated for several times by controlling local temperature (Fig. 1B). The salient feature allowed for catalysis and separation of $\mathbf{P N}_{\mathbf{4 2}} \mathbf{A}_{\mathbf{1 0}}$-C in aqueous system in a mild temperaturecontrollable way.

UV-vis. Apart from thermo-responsivity, $\mathbf{P N}_{\mathbf{4 2}} \mathbf{A}_{\mathbf{1 0}}-\mathbf{C}$ also exhibited UV stimuli-responsive behavior due to the presence of photosensitive azobenzene moiety. The photoresponsive
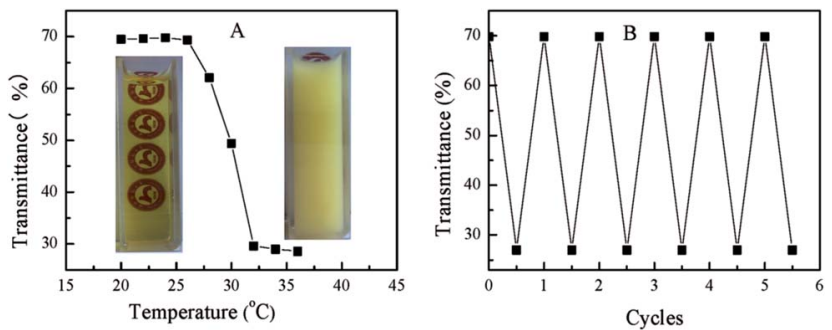

Fig. 1 Transmittance curves of the $\mathrm{PN}_{427} \mathrm{~A}_{10}-\mathrm{C}$ aqueous solutions (concentration: $0.8 \mathrm{mg} \mathrm{mL}^{-1},(\mathrm{~A})$ ), and optical transmittance at $440 \mathrm{~nm}$ of $\mathrm{PN}_{427} \mathrm{~A}_{10}-\mathrm{C}$ solution observed upon several cycles under heating at $32{ }^{\circ} \mathrm{C}$ and then cooling to $25^{\circ} \mathrm{C}(\mathrm{B})$. structural changes in $\mathbf{P N}_{\mathbf{4 2}} \mathbf{A}_{\mathbf{1 0}}-\mathbf{C}$ were then evaluated through spectral studies. The change in UV-vis absorption spectra of $\mathbf{P N}_{427} \mathbf{A}_{10}-\mathbf{C}$ upon UV irradiation $(365 \mathrm{~nm})$ were shown in Fig. 2. Before UV irradiation, a strong absorption band at $348 \mathrm{~nm}$ was observed which was ascribed to the $\pi-\pi *$ transition of trans-azo (Fig. 2A). ${ }^{12}$ The absorption band gradually decreased with UV irradiation, and showed an obvious blue shift to $334 \mathrm{~nm}$. Concomitantly, a new peak ascribed to $\mathrm{n}-\pi^{*}$ band of cis-azo appeared at around $443 \mathrm{~nm},{ }^{13}$ and gradually increased with prolonged irradiation time (Fig. 2A). The observation suggested the progressive isomerization of azobenzene from tans to cis upon UV irradiation..$^{13}$ After $220 \mathrm{~s}$ of UV light exposure, a photostationary state enriched by cis isomer was reached, and longer irradiation time caused no change in the UV-vis spectrum (Fig. 2A). The trans-azo could be obtained again when the irradiated sample was then kept in dark for $72 \mathrm{~h}$ (Fig. 2A). It indicated reversible photoisomerization of the azobenzene in $\mathbf{P N}_{\mathbf{4 2 7}} \mathbf{A}_{\mathbf{1 0}} \mathbf{-}^{-} \mathbf{C}$ between the trans- and cis-forms. Notably, the transcis photoisomerization of azobenzene could be repeated many times without fatigue and decomposition of the component (Fig. 2B).

${ }^{1} \mathbf{H}$ NMR. Photosensitivity of $\mathbf{P N}_{\mathbf{4 2 7}} \mathbf{A}_{\mathbf{1 0}}$-C was also investigated in detail by ${ }^{1} \mathrm{H}$ NMR spectroscopy carried out in DMSO- $d_{6}$. Dark-adapted sample was irradiated directly in the NMR tubes, by placing it $4 \mathrm{~cm}$ below $4 \mathrm{~W} 365 \mathrm{~nm}$ UV-lamp. After irradiation, the tube was put imminently into the NMR magnet, and the spectra were taken. As shown in ${ }^{1} \mathrm{H}$ NMR spectra (Fig. 3A), discernible aromatic proton signals associated with azobenzene group underwent obvious changes upon UV irradiation. Before UV treatment, $\mathbf{P N}_{\mathbf{4 2 7}} \mathbf{A}_{\mathbf{1 0}}-\mathbf{C}$ exhibited only the proton signals in the 7.90-7.79 ppm range in ${ }^{1} \mathrm{H}$ NMR spectrum, which was assigned as the 6- and 6'-position protons of trans-azo group (Fig. 3A(a)). Irradiation of UV light on the $\mathbf{P N}_{\mathbf{4 2}} \mathbf{A}_{\mathbf{1 0}}$-C solution induced a characteristic upfield shift of the typical signals (Fig. 3A(b-e)). Since overlapped protons in the bent cis-azo were shown at higher field than normal aromatic protons in the ${ }^{1} \mathrm{H}$ NMR spectra owning to the shielding effect of the overlapping benzene ring, the observed upfield shift was attributed to photoisomerization of trans-azo in $\mathbf{P N}_{\mathbf{4 2} 7} \mathbf{A}_{\mathbf{1 0}}$ - $\mathbf{C}$ to the cis-isomer which was overlapped at the 6 - and $6^{\prime}$-positions. ${ }^{5 a, c}$ The trans to cis isomerization also reduced the intramolecular distance
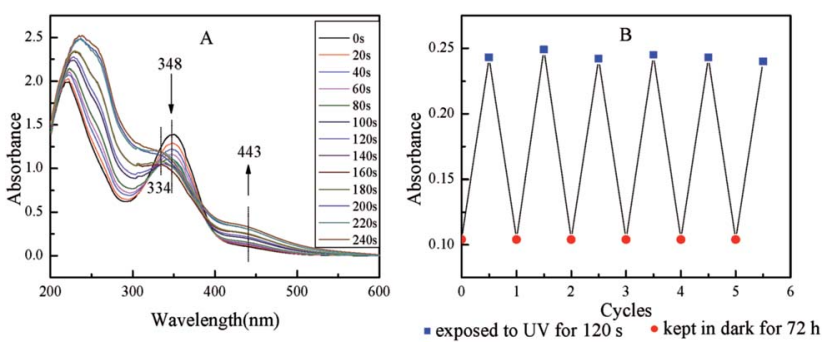

Fig. 2 UV-vis spectra of $\mathrm{PN}_{427} \mathrm{~A}_{10}-\mathrm{C}$ aqueous solution (concentration: $0.5 \mathrm{mg} \mathrm{mL}^{-1}$ ) upon UV irradiation ( $365 \mathrm{~nm}$ ) for different times (A), and optical absorbance at $443 \mathrm{~nm}$ of $\mathrm{PN}_{427} \mathrm{~A}_{10}-\mathrm{C}$ aqueous solution observed upon several cycles under irradiation at $365 \mathrm{~nm}$ for $140 \mathrm{~s}$ and keeping in dark for $72 \mathrm{~h} \mathrm{(B)}$. 


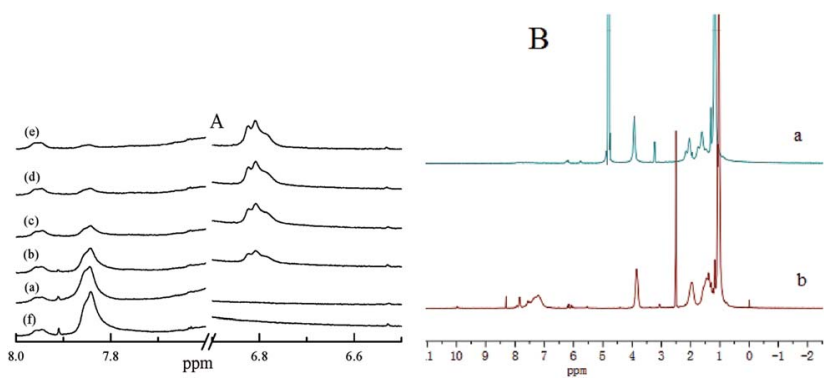

Fig. 3 Changes in ${ }^{1} \mathrm{H}$ NMR spectra of $\mathrm{PN}_{427} \mathrm{~A}_{10}-\mathrm{C}$ upon photoisomerization in DMSO- $d_{6}$ (A) (at dark-adapted state (a), after 1 min of UV irradiation (b), after 3 min of UV irradiation (c), after 5 min of UV irradiation (d), after 10 min of UV irradiation (e), and the UV-treated samples kept in dark for $72 \mathrm{~h}(\mathrm{f})) ;{ }^{1} \mathrm{H}$ NMR spectra of dark-adapted $\mathrm{PN}_{427} \mathrm{~A}_{10}-\mathrm{C}(\mathrm{B})$ in $\mathrm{D}_{2} \mathrm{O}(\mathrm{a})$ and in $\mathrm{DMSO}-d_{6}$ (b).

between aromatic rings of azobenzene and slowed the rotation around $\mathrm{C}-\mathrm{N}$ bonds, leading to better separation of the proton signals. ${ }^{14}$ Therefore, multiple upfield signals at $6.75,6.80$, and $6.84 \mathrm{ppm}$ progressively appeared when $\mathbf{P N}_{\mathbf{4 2}} \mathbf{A}_{\mathbf{1 0}}-\mathrm{C}$ was irradiated by UV light (Fig. $3 \mathrm{~A}(\mathrm{~b}-\mathrm{e})$ ). The composition of cis-isomer increased with the irradiation of UV light and reached the photostationary state after irradiation for $10 \mathrm{~min}$ (Fig. 3A(e)). Then, the ${ }^{1} \mathrm{H}$ NMR spectra could revert to the initial state, after the UV-treated $\mathbf{P N}_{\mathbf{4 2}} \mathbf{\mathbf { A } _ { \mathbf { 1 0 } }}-\mathbf{C}$ was held in dark for $72 \mathrm{~h}$ (Fig. $3 \mathrm{~A}(\mathrm{f}$ )). It demonstrated the reversible trans-cis photoisomerization of azobenzene moiety in $\mathbf{P N}_{\mathbf{4 2}} \mathbf{A}_{\mathbf{1 0}}$-C.

Interestingly, dark-adapted $\mathbf{P N}_{\mathbf{4 2}} \mathbf{A}_{\mathbf{1 0}}-\mathbf{C}$ in DMSO- $d_{6}$ and $\mathrm{D}_{2} \mathrm{O}$ gave different ${ }^{1} \mathrm{H}$ NMR spectra, as shown in Fig. 3B. ${ }^{1} \mathrm{H}$ NMR spectrum of $\mathbf{P N}_{427} \mathbf{A}_{10}-\mathbf{C}$ in DMSO- $d_{6}$ exhibited the distinct $\mathrm{H}$ signals of PNIPAAm moiety $\left(\delta=3.84 \mathrm{ppm}, \mathrm{O}=\mathrm{CNHCH}\left(\mathrm{CH}_{3}\right)_{2}\right)$, azobenzene group $(\delta=7.84 \mathrm{ppm}, \mathrm{N}=\mathrm{N}-\mathrm{Ph}-H)$, and Ti(salen) unit $(\delta=1.24$, cyclohexyl- $H)$. It indicated the presence of hydrophilic PNIPAAm block, hydrophobic azobenzene block, and catalytically active Ti(salen) unit in $\mathbf{P N}_{\mathbf{4 2 7}} \mathbf{A}_{\mathbf{1 0}}$-C. Whereas, the $\mathrm{H}$ signals associated with azobenzene and Ti(salen) moieties almost disappeared when ${ }^{1} \mathrm{H}$ NMR spectrum was carried out in $\mathrm{D}_{2} \mathrm{O}$. The difference gave an evidence for the effective shielding of azobenzene and $\mathrm{Ti}(\mathrm{salen})$ groups from the aqueous environment upon self-assembly of $\mathbf{P N}_{\mathbf{4 2}} \mathbf{A}_{\mathbf{1 0}}$-C in water. ${ }^{1{ }^{10,15}}$ Hydrophobic shielding of active site made the $\mathbf{P N}_{\mathbf{4 2}} \mathbf{A}_{\mathbf{1 0}}$ - $\mathbf{C}$ an efficient enzyme-mimetic metallomicelle for asymmetric catalysis in water.

CMC determination. CMC determination provided strong evidence for the self-assembly behaviors of $\mathbf{P N}_{\mathbf{4 2}} \mathbf{A}_{\mathbf{1 0}}-\mathbf{C}$, since amphiphiles would self-assemble in water when the concentration of solutions were above the CMC value. Surface tension measurements over a wide range of concentrations were used to determine the CMC value of $\mathbf{P N}_{\mathbf{4 2}} \mathbf{A}_{\mathbf{1 0}}$-C. Fig. 4 showed the plots of surface tension as a function of logarithm of concentration for $\mathbf{P N}_{\mathbf{4 2 7}} \mathbf{A}_{\mathbf{1 0}}-\mathbf{C}$ at dark-adapted state or under UV irradiation in water at $25{ }^{\circ} \mathrm{C}$. Clearly, the surface tension decreased dramatically as the concentration of catalyst increased, and then it didn't change substantially as a function of concentration of catalyst. The inflection point at characteristic concentration gave the information on $\mathrm{CMC}$ value of corresponding sample.
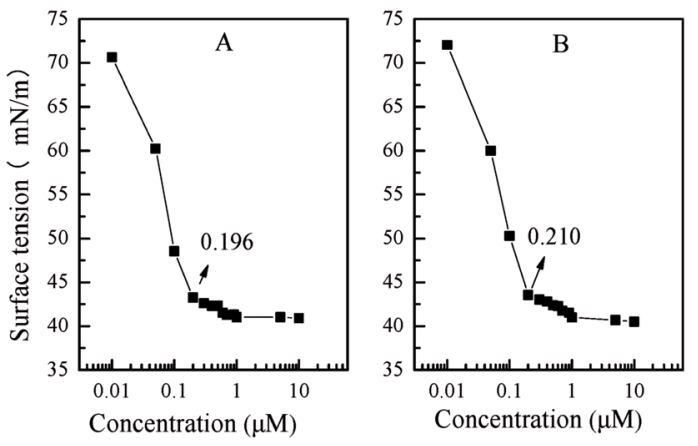

Fig. 4 Plots of surface tension against logarithm of concentration for $\mathrm{PN}_{427} \mathrm{~A}_{10}-\mathrm{C}$ in water at $25^{\circ} \mathrm{C}$ (at dark-adapted state (A), after 5 min of UV irradiation (B)).

The CMC value of $\mathbf{P N}_{\mathbf{4 2 7}} \mathbf{A}_{\mathbf{1 0}}-\mathrm{C}$ at dark-adapted state was thus determined to be $0.196 \mathrm{mmol} \mathrm{L}^{-1}$ (Fig. 4A). Notably, the CMC value slightly increased to $0.210 \mathrm{mmol} \mathrm{L} \mathrm{L}^{-1}$ when the darkadapted $\mathbf{P N}_{\mathbf{4 2}} \mathbf{A}_{\mathbf{1 0}}-\mathbf{C}$ aqueous solution was exposed to UV irradiation for 5 min (Fig. 4B). Photoisomerization of azobenzene from trans-form to more hydrophilic cis-form should account for the increased CMC value. ${ }^{16}$ The results suggested the UVcontrolled self-assembly behavior of $\mathbf{P N}_{\mathbf{4 2}} \mathbf{A}_{\mathbf{1 0}}$-C.

TEM. TEM images gave direct information of the selfassembly of $\mathbf{P N}_{\mathbf{4 2 7}} \mathbf{A}_{\mathbf{1 0}}$ - $\mathbf{C}$ in water, as well as the morphological change induced by UV irradiation (Fig. 5). As expected, driven by hydrophobic interaction and the $\pi-\pi$ stacking of azobenzene block, $\mathbf{P N}_{\mathbf{4 2 7}} \mathbf{A}_{\mathbf{1 0}}$-C self-assembled in water, forming metallomicelles in a nanometer scale. Light-induced changes in azobenzene conformation adjusted the hydrophilic-hydrophobic balance of $\mathbf{P N}_{\mathbf{4 2 7}} \mathbf{A}_{\mathbf{1 0}}$-C. As a result, morphology and/or size of the metallomicelles were controlled by UV irradiation. In the absence of UV irradiation, dark-adapted $\mathbf{P N}_{\mathbf{4 2 7}} \mathbf{A}_{\mathbf{1 0}}$-C selfassembled into spherical nanoparticular (diameter of $c a .2 \mathrm{~nm}$ ) in water exposing the hydrophilic NIPAAm to water, while the hydrophobic azobenzene and Ti(salen) units packed together to form a hydrophobic core (Fig. 5a). The nanoassemblies presented a micelle to vesicle transition behavior upon UV treatment (Fig. 5b-d). Vesicles were observed when the sample was exposed to UV light for $10 \mathrm{~s}$ (Fig. 5b). The morphological transition accomplished after UV irradiation for $30 \mathrm{~s}$, giving almost

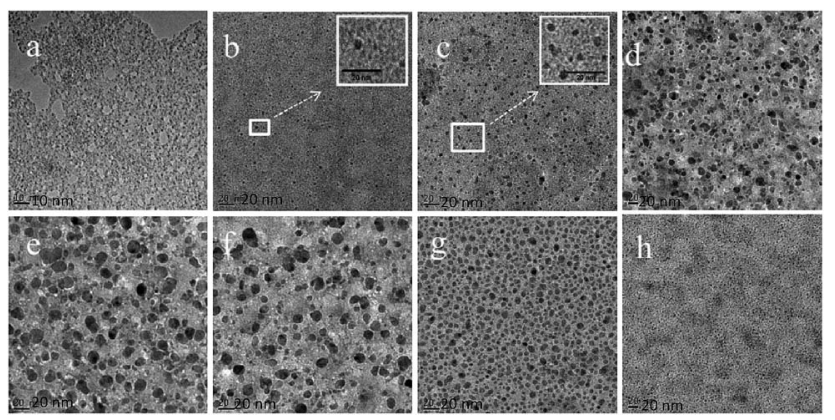

Fig. 5 TEM images of $\mathrm{PN}_{427} \mathrm{~A}_{10}-\mathrm{C}$ in a dark-adapted state (a) and after UV irradiation for $10 \mathrm{~s}(\mathrm{~b}), 30 \mathrm{~s}(\mathrm{c}), 40 \mathrm{~s}(\mathrm{~d}), 60 \mathrm{~s}$ (e), $70 \mathrm{~s}$ (f), $90 \mathrm{~s}(\mathrm{~g})$, and the UV-treated $\mathrm{PN}_{427} \mathrm{~A}_{10}-\mathrm{C}$ kept in dark for $72 \mathrm{~h}(\mathrm{~h})$. 
uniform vesicles with size of ca. $6 \mathrm{~nm}$ (Fig. 5c). UV-induced isomerization of azo-moiety from trans- to cis-form was responsible for this morphological transition due to the differences in geometry and polarity between the two isomers. As we all know, the bend cis-azo occupied a larger volume than the rod-like trans-form. ${ }^{\mathbf{1 3 d}, \mathbf{1 7}}$ This implied that the UV-induced isomerization of azo-moiety increased the steric hindrance between azo-molecule in the hydrophobic core, which weakened their $\pi-\pi$ staking interaction. Furthermore, hydrophobicity of azo-molecule also decreased when trans-form were transformed into cis-form under UV light. ${ }^{5 e}$ The reduced $\pi-\pi$ staking and hydrophobic interactions made the azobenzene groups have no ability to accumulate tightly in $\mathbf{P N}_{\mathbf{4 2 7}} \mathbf{A}_{\mathbf{1 0}}-\mathrm{C}$ selfassemblies. As a result, the micellar structure with a monolayered arrangement of hydrophilic and hydrophobic chains was unable to stabilize the self-assemblies. The vesicle structure thus occurred with the formation of the bilayer, in which hydrophobic segments stacked inside and the remaining hydrophilic NIPAAm block dangle in the surrounding aqueous solution.

Interestingly, the adjacent vesicles underwent close contact and mergence to become the bigger vesicles, when the UV irradiation time was prolonged from 30 to $60 \mathrm{~s}$ (Fig. $5 \mathrm{~d}$ and e). Larger vesicles with size greater than $20 \mathrm{~nm}$ were observed when the sample was exposed to UV light for $60 \mathrm{~s}$. Increasing cisisomer in vesicular membrane was the ultimate cause of this fusion process. As the cis-isomer increasing, a larger volume was needed for the cis-form to exist in stable form. It thus brought a loose stacking formation in the vesicular membrane, or even disrupted the bilayer of vesicles. In addition, the surface area of vesicles should expand as a result of the transition from tight to loose packing, leading to an increase in instantaneous surface free energy. Therefore, fusion was the most likely pathway for the vesicles to become stable and reduce their surface free energy. Furthermore, fusion proceeded through a highly bent stalk intermediate, which was formed when hydrophobic tails from two apposing membranes came into contact via a fluctuation and made a hydrophobic bridge between them. ${ }^{\mathbf{1 8}}$ The formation of the stalk structure required overcoming the free energy barriers. In fact, the change from tight to loose packing could increase the entropy without adversely affecting the enthalpy. It thus lowered the free energy barriers, which benefited the fusion process. ${ }^{18}$ In other words, the defects in loose packing state with more structural flexibility and plasticity may facilitate the restructuring of the $\mathbf{P N}_{\mathbf{4 2 7}} \mathbf{A}_{\mathbf{1 0}}-\mathbf{C}$ bilayer in the fusion process. Notably, the regions of defects were not large enough to cause the rupture of individual vesicle, since the rupture would overcome the entanglement of polymer chains and increase the surface free energy. The disruption extent of membranes gradually increased with continuous irradiation. When the vesicles with large disruption areas appeared, rupture of vesicular membrane took place. Subsequently, the disintegrated fragments rearranged to a majority of small vesicles by virtue of the hydrophobic interaction. Indeed, after the sample was irradiated for $60 \mathrm{~s}$, those larger vesicles with damages and defects severely ruptured until almost complete disintegration occurred, and then rearranged to form a large number of very small vesicles (Fig. $5 \mathrm{~g} v s$. f). Similar observations of the photo-induced process including fusion, disintegration and rearrangement have also been reported in the literature. ${ }^{19}$ Upon keeping the UV-treated $\mathbf{P N}_{\mathbf{4 2 7}} \mathbf{A}_{\mathbf{1 0}}-\mathbf{C}$ in dark for $72 \mathrm{~h}$, spherical nanoparticular emerged again with a size close to $2.0 \mathrm{~nm}$ (Fig. 5h). Such morphological changes indicated the responsiveness of the metallomicelles towards UV light, which has the potential to adjust catalyst concentration and/or accessibility in real-time, allowing for fine control of the asymmetric sulfoxidation in water.

DLS. Size and morphological changes of $\mathbf{P N}_{\mathbf{4 2 7}} \mathbf{A}_{10}-\mathbf{C}$ nanoassemblies under the influence of UV irradiation were also investigated by DLS. The hydrodynamic diameter and size distribution under different irradiation conditions were shown in Fig. 6. Before UV irradiation, $\mathbf{P N}_{\mathbf{4 2 7}} \mathbf{A}_{\mathbf{1 0}}$-C aqueous solution showed the aggregate with hydrodynamic diameter $\left(D_{\mathrm{h}}\right)$ of $c a$. $23.5 \mathrm{~nm}$ (polydispersity indexes, PDI $=0.143$ ). When the $\mathbf{P N}_{427} \mathbf{A}_{10}-\mathbf{C}$ aqueous solution was exposed to UV light for $30 \mathrm{~s}$, the size of the metallomicelles increased to $44.1 \mathrm{~nm}$ (PDI = 0.164). Great change in the metallomicelle size reflected a morphological transformation from micelle to vesicle, as confirmed by TEM. The $D_{\mathrm{h}}$ increased continually to $58.3 \mathrm{~nm}$ $(\mathrm{PDI}=0.179)$ when the UV irradiation time was prolonged to $60 \mathrm{~s}$, due to photo-induced fusion of vesicles during the irradiation. After UV treatment for $90 \mathrm{~s}$, the size of $\mathbf{P N}_{\mathbf{4 2 7}} \mathbf{A}_{\mathbf{1 0}}-\mathbf{C}$ metallomicelle decreased to $32.7 \mathrm{~nm}$ (PDI $=0.236$ ) which indicated a disintegration and rearrangement of the larger vesicle. Relatively higher PDI value $(0.236)$ was probably due to the relative inhomogeneity of rearranged vesicle. ${ }^{20}$ These observations were in complete agreement with the results obtained in TEM images.

\section{Catalytic performances}

Encouraged by the photo-induced change in morphology of $\mathbf{P N}_{\mathbf{4 2 7}} \mathbf{A}_{10}-\mathbf{C}$, the self-assembled Ti(salen)-containing metallomicelles was employed as the photo-sensitive bio-nanoreactor for controlled catalysis of asymmetric sulfoxidation in water. Phenyl methyl sulfide was used as a substrate to investigate the

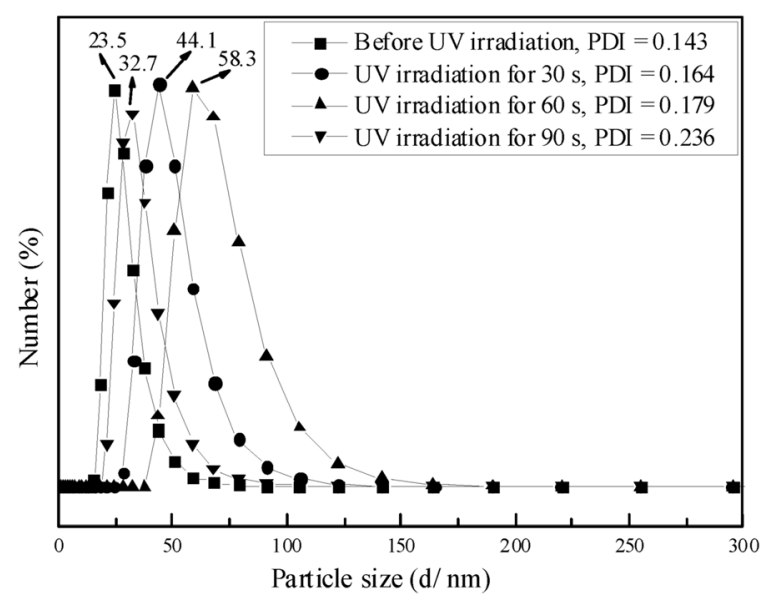

Fig. 6 Size distribution of self-assembled $\mathrm{PN}_{427} \mathrm{~A}_{10}-\mathrm{C}$ in water at a concentration of $0.5 \mathrm{mg} \mathrm{mL}^{-1}$ under different UV irradiation time. 
photo-mediated catalytic performance of $\mathbf{P N}_{\mathbf{4 2 7}} \mathbf{A}_{\mathbf{1 0}}$-C. Before reaction, dark-adapted $\mathbf{P N}_{\mathbf{4 2} 7} \mathbf{A}_{\mathbf{1 0}}$-C in which all the azobenzene chromophores were in trans-state was exposed to UV light $(\lambda=$ $365 \mathrm{~nm}$ ) for a certain time, and then wrapped with aluminum foil to avoid the disturbance of natural light. The results are presented in Table 1. Traditional chiral salen $\mathrm{Ti}^{\mathrm{IV}}$ complex (denoted as neat complex, Chart 1) was also employed for comparison.

As expected, $\mathbf{P N}_{\mathbf{4 2}} \mathbf{\mathbf { A } _ { \mathbf { 1 0 } }}$-C-based metallomicelles significantly accelerated the asymmetric oxidation of methyl aryl sulfides in water using $\mathrm{H}_{2} \mathrm{O}_{2}$ as oxygen source, giving high activity and remarkable selectivity (in terms of chemo- and enantioselectivity) (Table 1, entries 1-10). Only $0.1 \mathrm{~mol} \%$ of $\mathbf{P N}_{\mathbf{4 2}} \mathbf{A}_{\mathbf{1 0}}-\mathbf{C}$ was sufficient for giving almost quantitative yield $(>99 \%)$ of phenyl methyl sulfoxide with outstanding chiral induction (99\%) when catalyst was treated with UV irradiation for 30, 60, or $90 \mathrm{~s}$ (Table 1, entries 4,7 , and 10). In contrast, extremely low conversion (8\%) with disappointing chemoselectivity (86\%) and ee value $(83 \%)$ was obtained under identical conditions when the reaction was catalyzed by neat complex (Table 1, entry 11). The results demonstrated the advantages of metallomicellar catalytic approach over self-assembled $\mathbf{P N}_{\mathbf{4 2}} \mathbf{A}_{\mathbf{1 0}}$-C. The formed metallomicelles not only showed good water-solubility, but also possessed a hydrophobic compartmentalized structure which allowed effectively shielding active sites from aqueous environment, reminiscent of enzyme. ${ }^{21}$ Dense chiral salen $\mathrm{Ti}^{\mathrm{IV}}$ complexes confined in the hydrophobic domain may enforce a cooperative reaction pathway favourable for the asymmetric sulfoxidation. ${ }^{3 c, 20,22}$ Substrates were also effectively sequestered by the hydrophobic compartment from the surrounding aqueous environment, creating a highly concentrated environment for efficient catalysis. Furthermore, synergistic effects between the metal-catalyzed center and the hydrophobic microenvironment in the metallomicelle led to high selectivity. ${ }^{23}$

Photo-responsive behavior of the metallomicelles made catalytic efficiency of $\mathbf{P N}_{\mathbf{4 2}} \mathbf{A}_{\mathbf{1 0}}$-C sensitive to UV irradiation. Indeed, the catalytic activity of $\mathbf{P N}_{\mathbf{4 2 7}} \mathbf{A}_{\mathbf{1 0}}$ - $\mathbf{C}$ was adjusted by UV irradiation in the aqueous asymmetric sulfoxidation. Before UV treatment, dark-adapted $\mathbf{P N}_{\mathbf{4 2 7}} \mathbf{A}_{\mathbf{1 0}}$ - $\mathrm{C}$ gave $82 \%$ conversion of phenyl methyl sulfide in water within $75 \mathrm{~min}$ (Table 1, entry 1). UV irradiation mediated the catalytic performance of $\mathbf{P N}_{\mathbf{4 2}} \mathbf{A}_{\mathbf{1 0}}{ }^{-}$ $\mathbf{C}$ in the aqueous asymmetric sulfoxidation (Table 1, entries 110). In particular, almost quantitative yield $(>99 \%)$ of $(R)$-phenyl methyl sulfoxide was obtained when the dark-adapted $\mathbf{P N}_{\mathbf{4 2}} \mathbf{A}_{\mathbf{1 0}}{ }^{-}$ C was exposed to UV light for $30 \mathrm{~s}$ (Table 1, entry 4). Enhanced activity should be related to the micelle to vesicle transition behavior of $\mathbf{P N}_{\mathbf{4 2 7}} \mathbf{A}_{\mathbf{1 0}}$-C upon UV treatment, as shown in TEM images. Despite both confined catalysis, vesicles represented bubble-like structures in which a water-containing interior was enclosed by a double-layer membrane. The bilayer membrane was a more conducive structure for sequestering substrates from the surrounding aqueous environment, creating a highly concentrated environment favorable for efficient sulfoxidation. ${ }^{3 c}$ Varied UV irradiation time resulted in the variation of catalytic efficiency of $\mathbf{P N}_{\mathbf{4 2}} \mathbf{A}_{\mathbf{1 0}}$-C (Table 1, entries 5-10). Quantitative yield of $(R)$-phenyl methyl sulfoxide was also observed when $\mathbf{P N}_{\mathbf{4 2} 7} \mathbf{A}_{\mathbf{1 0}} \mathbf{-} \mathbf{C}$ was treated by UV irradiation for 60 or $90 \mathrm{~s}$.

Table 1 Results of the asymmetric sulfoxidation of alkyl aryl sulfides with $\mathrm{H}_{2} \mathrm{O}_{2}$ over chiral salen Tilv catalysts under different UV-irradiation time ${ }^{a}$

\begin{tabular}{|c|c|c|c|c|c|c|c|c|}
\hline Entry & Catalyst & Substrates & Products & UV-irradiation time (s) & $T(\min )$ & Conv. ${ }^{b} / \%$ & Sel. ${ }^{c} / \%$ & $\mathrm{ee}^{d} / \%$ \\
\hline 1 & $\mathbf{P N}_{427} \mathbf{A}_{10}-\mathrm{C}$ & & & 0 & 75 & 82 & 95 & $99(R)$ \\
\hline 2 & $\mathbf{P N}_{427} \mathbf{A}_{10}-\mathrm{C}$ & & & 10 & 75 & 76 & 99 & $99(R)$ \\
\hline 4 & $\mathbf{P N}_{427} \mathbf{A}_{10}-\mathrm{C}$ & & 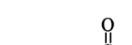 & 30 & 75 & 99 & 99 & $99(R)$ \\
\hline 5 & $\mathbf{P N}_{427} \mathbf{A}_{10}-\mathrm{C}$ & & & 40 & 75 & 76 & 99 & $99(R)$ \\
\hline 6 & $\mathbf{P N}_{42} \mathbf{A}_{10}-\mathrm{C}$ & & & 50 & 75 & 85 & 99 & $99(R)$ \\
\hline 9 & $\mathbf{P N}_{42} \mathbf{A}_{10}-\mathrm{C}$ & & & 80 & 75 & 86 & 99 & $99(R)$ \\
\hline 10 & $\mathbf{P N}_{427} \mathbf{A}_{10}-\mathrm{C}$ & & & 90 & 75 & 98 & 99 & $99(R)$ \\
\hline 11 & Neat complex & & & - & 75 & 8 & 86 & $83(R)$ \\
\hline 12 & $\mathbf{P N}_{427} \mathbf{A}_{10}-\mathrm{C}$ & & & 0 & 100 & 54 & 90 & $97(R)$ \\
\hline 13 & $\mathbf{P N}_{427} \mathbf{A}_{10}-\mathrm{C}$ & & & 60 & 100 & 90 & 91 & $97(R)$ \\
\hline 14 & Neat complex & & & - & 100 & 35 & 66 & $82(R)$ \\
\hline 18 & $\mathbf{P N}_{427} \mathbf{A}_{10^{-}} \mathrm{C}$ & & & 0 & 105 & 75 & 98 & $99(R)$ \\
\hline 19 & $\mathbf{P N}_{427} \mathbf{A}_{10}-\mathrm{C}$ & & & 60 & 105 & 91 & 99 & $99(R)$ \\
\hline 20 & Neat complex & $\mathrm{DCH}_{3}$ & & - & 105 & 43 & 91 & $76(R)$ \\
\hline
\end{tabular}

\footnotetext{
${ }^{a}$ Catalyst $\left(0.1 \mathrm{~mol} \%\right.$ of substrate, based on titanium content), substrate (1.0 mmol), $\mathrm{H}_{2} \mathrm{O}_{2}(30 \mathrm{wt} \%, 1.2$ mmol, slowly added within $15 \mathrm{~min}), \mathrm{H}{ }_{2} \mathrm{O}$ $(2.0 \mathrm{~mL}), 25{ }^{\circ}$ C. $^{b}$ Determined by GC. ${ }^{c}$ Chemoselectivity to sulfoxide (determined by GC). ${ }^{d}$ Determined by HPLC (Daicel Chiralpak AD column).
} 
Various activities should be related to the photo-induced change in morphology of the metallomicelles. During the irradiation of UV light, the vesicles underwent photo-provoked disruption, fusion, disintegration and rearrangement in water. Relatively integrated double-layer membrane structure of the vesicles was observed when $\mathbf{P N}_{\mathbf{4 2 7}} \mathbf{A}_{\mathbf{1 0}}$-C was treated by UV light for 60 or $90 \mathrm{~s}$, which was favourable for the metallomicellar catalysis. The UV-responsive catalytic efficiency of $\mathbf{P N}_{\mathbf{4 2 7}} \mathbf{A}_{\mathbf{1 0}}-\mathbf{C}$ made controlled catalysis of asymmetric sulfoxidation in water come true.

Kinetics was used to further investigate the advantages of the metallomicellar catalysis approach in aqueous reaction, as well as the photo-controlled catalytic performance of $\mathbf{P N}_{\mathbf{4 2 7}} \mathbf{A}_{\mathbf{1 0}}$-Cbased metallomicelle. Corresponding kinetic curves and rate curves of asymmetric sulfoxidation of methyl phenyl sulfide over $\mathbf{P N}_{427} \mathbf{A}_{10}-\mathbf{C}$ in water (after $60 \mathrm{~s}$ of UV irradiation, after $40 \mathrm{~s}$ of UV irradiation, and at dark-adapted state) were shown in Fig. 7. Obviously, gradient increase in conversion of sulfide was observed over $\mathbf{P N}_{\mathbf{4 2 7}} \mathbf{A}_{\mathbf{1 0}}$-C either at dark-adapted state or upon UV treatment, when asymmetric sulfoxidations were performed in water (Fig. 7A(a-c)). The corresponding rate constant $\left(k_{\text {obs }}\right)$ initially rose rapidly due to the increasing concentration of substrate in hydrophobic microenvironment, went through a maximum, and then drastically decreased due to a dilution effect (Fig. 7B(a-c)). ${ }^{24}$ The featured kinetics demonstrated confined catalysis of asymmetric sulfoxidation in water over $\mathbf{P N}_{427} \mathbf{A}_{10}$-C. To evaluate the advantages of metallomicelle, we carried out the reaction with dark-adapted $\mathbf{P N}_{\mathbf{4 2 7}} \mathbf{A}_{\mathbf{1 0}}-\mathbf{C}$ in ethanol, a solvent in which $\mathbf{P N}_{\mathbf{4 2 7}} \mathbf{A}_{\mathbf{1 0}}-\mathbf{C}$, sulfide and $\mathrm{H}_{2} \mathrm{O}_{2}$ could be well dissolved. As expected, at the same catalyst concentration, dark-adapted $\mathbf{P N}_{\mathbf{4 2}} \mathbf{A}_{\mathbf{1 0}}-\mathbf{C}$ in ethanol was less efficient than that in water, although the ethanol-based system was homogeneous (Fig. 7d vs. c). Logically, in ethanol, $\mathbf{P N}_{\mathbf{4 2 7}} \mathbf{A}_{\mathbf{1 0}}-\mathbf{C}$ may gather together just via $\pi-\pi$ stacking of azobenzene species from neighbouring catalyst, rather than packing to form the confined hydrophobic pocket. It thus couldn't sequester organic substrate from surrounding environment through hydrophobic effect. Low local concentration of substrate in the ethanol system resulted in the unsatisfied activity. Interestingly,
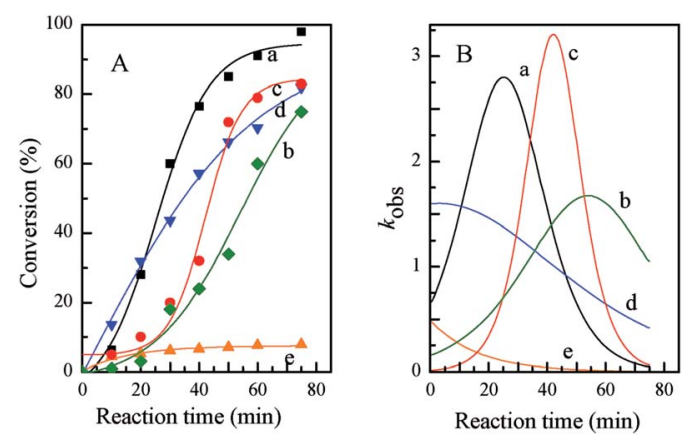

Fig. 7 Kinetic curves (A) and rate curves (B) of asymmetric sulfoxidation of methyl phenyl sulfide over $\mathrm{PN}_{427} \mathrm{D}_{10}-\mathrm{C}$ in water (after $60 \mathrm{~s}$ of UV irradiation (a), after $40 \mathrm{~s}$ of UV irradiation (b), and at dark-adapted state (c)), over dark-adapted $\mathrm{PN}_{427} \mathrm{D}_{10}-\mathrm{C}$ (d) and over neat complex (e) in ethanol. despite also homogeneous system, traditional neat complex in ethanol was far less efficient than $\mathbf{P N}_{\mathbf{4 2 7}} \mathbf{A}_{\mathbf{1 0}}$-C under identical conditions (Fig. 7e vs. d). Extremely low $k_{\text {obs }}$ value was observed over the traditional neat complex (Fig. 7B(e)). It was reasonable that traditional neat complex without azobenzene moiety could not gather together in ethanol system to achieve concentrated catalytic sites and organic substrate. Low local concentration of catalytic species and sulfides were insufficient for the efficient sulfoxidation. The results were consistent with our hypothesis that the high local concentrations of catalytic species and substrate were crucial for this system to be active, and this was only achieved in the metallomicellar system in water. Notably, despite all metallomicellar catalysis, the $k_{\text {obs }}$ over $\mathbf{P N}_{\mathbf{4 2 7}} \mathbf{A}_{\mathbf{1 0}}-\mathbf{C}$ varied with the UV irradiation time, and highest efficiency was observed when $\mathbf{P N}_{\mathbf{4 2 7}} \mathbf{A}_{\mathbf{1 0}}-\mathbf{C}$ was treated with UV light for $60 \mathrm{~s}$ (Fig. 7a). The observations did agree with the ability to photomodulate the activity of $\mathbf{P N}_{\mathbf{4 2 7}} \mathbf{A}_{\mathbf{1 0}}$ - $\mathbf{C}$ in asymmetric sulfoxidation in water.

The UV-responsive catalytic efficiency over $\mathbf{P N}_{\mathbf{4 2 7}} \mathbf{A}_{10}-\mathbf{C}$ was also noticeable for other aryl methyl sulfides, such as ethyl phenyl sulfide, methyl $p$-methoxyphenyl sulfide, and methyl $o$ methoxyphenyl sulfide. $\mathbf{P N}_{\mathbf{4 2 7}} \mathbf{A}_{\mathbf{1 0}}-\mathbf{C}$ after $60 \mathrm{~s}$ of UV irradiation always gave high activity than the dark-adapted $\mathbf{P N}_{\mathbf{4 2 7}} \mathbf{A}_{\mathbf{1 0}}-\mathbf{C}$ in corresponding sulfoxidations (Table 1 , entry $13 v s$. 12, entry 16 vs. 15 , entry 19 vs. 18). All the aryl methyl sulfides get quantitatively oxidized to the corresponding sulfoxides with excellent chemo- (91-99\%) and enantioselectivity (97-99\%) within 105 min in water with the employment of UV-treated $\mathbf{P N}_{\mathbf{4 2 7}} \mathbf{A}_{\mathbf{1 0}}-\mathbf{C}$ (Table 1, entries 13, 16, and 19). Especially, almost quantitative chiral induction to $(R)$-sulfide $(>99 \%)$ was observed for the methyl $o$-methoxyphenyl sulfide over the $\mathbf{P N}_{\mathbf{4 2 7}} \mathbf{A}_{\mathbf{1 0}}$-C after $60 \mathrm{~s}$ of UV irradiation (Table 1, entry 16). The results suggested the universality of $\mathbf{P N}_{\mathbf{4 2 7}} \mathbf{A}_{\mathbf{1 0}}$-C in green asymmetric sulfoxidation. Traditional neat complex was also inactive in the aqueous sulfoxidations systems due to water-incompatibility (Table 1, entries 14, 17, and 20).

Apart from photo-responsive catalytic activity, $\mathbf{P N}_{\mathbf{4 2 7}} \mathbf{A}_{\mathbf{1 0}}-\mathbf{C}$ also exhibited the reversibility of thermal-driven water-
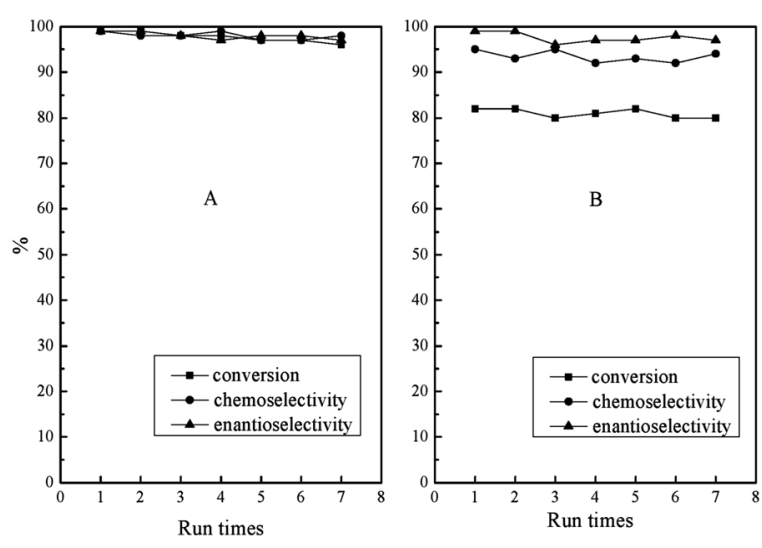

Fig. 8 Reuse of $\mathrm{PN}_{427} \mathrm{~A}_{10}-\mathrm{C}$ after $60 \mathrm{~s}$ of UV treatment (A) or in darkadapted state (B) in asymmetric sulfoxidation of methyl phenyl sulfide in water using aq. $\mathrm{H}_{2} \mathrm{O}_{2}$ as an oxidant at $25^{\circ} \mathrm{C}$. 
solubility switching, as shown in Fig. 1. The salient features allowed for the facile recovery of $\mathbf{P N}_{\mathbf{4 2 7}} \mathbf{A}_{\mathbf{1 0}}$-C from the aqueous phase by thermo-controlled separation. Especially, the LCST close to room temperature made the recovery of catalyst for reuse under mild local temperature (at $32{ }^{\circ} \mathrm{C}$ ). Fig. 8 showed the reusability of $\mathbf{P N}_{\mathbf{4 2 7}} \mathbf{A}_{\mathbf{1 0}}$-C after 60 s of UV treatment or in darkadapted state in asymmetric oxidation of methyl phenyl sulfide in water.

To our delight, the catalyst either at dark-adapted state or upon UV treatment could be reused up to seven times without significant loss in activity and selectivity. Leaching test of catalyst revealed negligible leaching loss of titanium species (less than $0.1 \mathrm{ppm}$ by ICP) to reaction medium during the oxidation. Chemical analysis of the recovered $\mathbf{P N}_{\mathbf{4 2}} \mathbf{A}_{10}-\mathbf{C}$ gave the titanium content $\left(0.0172 \mathrm{mmol} \mathrm{g}^{-1}\right)$ almost identical to that of the fresh one $\left(0.018 \mathrm{mmol} \mathrm{g}^{-1}\right)$. Furthermore, oxidative decomposition of $\mathbf{P N}_{\mathbf{4 2 7}} \mathbf{A}_{\mathbf{1 0}}$ - $\mathbf{C}$, a main reason for the deactivation of chiral salen $\mathrm{Ti}^{\mathrm{IV}}$ catalyst in $\mathrm{H}_{2} \mathrm{O}_{2}$-based oxidation, ${ }^{25}$ also did not occur during the reaction. The excellent stability of catalyst should arise from the shielding of the chiral salen $\mathrm{Ti}^{\mathrm{IV}}$ complex in a hydrophobic pocket, which protected the catalytic site from oxidative decomposition by excluding excess $\mathrm{H}_{2} \mathrm{O}_{2}$ from the hydrophobic compartment.

\section{Conclusions}

In conclusion, controllable metallomicellar catalysis of aqueous asymmetric sulfoxidation has been realized by using photoresponsive self-assembled metallomicelle which contained azobenzene and chiral salen $\mathrm{Ti}^{\mathrm{IV}}$ complexes in the hydrophobic compartment. Catalytic activity of the metallomicelle could be precisely controlled by UV irradiation time, due to the UVinduced change in morphology which adjusted catalyst concentration and/or accessibility in real-time. Furthermore, the catalysts could be facilely recovered from the aqueous system for efficient reuse by adjusting the local temperature. The photo-controlled catalytic efficiency, as well as outstanding reusability, made the metallomicelle highly promising for controllable catalysis of various organic reactions in water. And also, the responsive self-assembly approach inspired researchers to develop other controllable metallomicellar catalysis system for a much wider range of application.

\section{Experimental section}

\section{Materials and reagents}

Tetra-isopropyl titanate, aminoazobenzene and methyl aryl sulfides were obtained by J\&K. $N, N$-Azobis(isobutyronitrile) (AIBN), NIPAAm, 2-aminoethanethiol hydrochloride, and $\mathrm{L}(+)$ tartaric acid were purchased from Acros. 2-tert-Butyl phenol was purchased from Alfa Aesar. Other commercially available chemicals were laboratory grade reagents from local suppliers. All solvents were purified by standard procedures. NIPAAm was purified by recrystallization from $n$-hexane and dried in vacuo before use.

\section{Methods}

UV-vis spectroscopy was carried out on a UV-vis Agilent 8453 spectrophotometer. Molecular weight of the synthesized copolymers were obtained by gel permeation chromatography (GPC) on an Alltech Instrument (Alltech, America) equipped with an Alltech ELSD 800 detector. NMR spectrum of samples was recorded on a BRUKER AVANCE-500 spectrometer with TMS as an internal standard. The measurements were repeated for at least three times to ensure good reproducibility. The critical micellization concentration (CMC) was investigated using the surface tension method. The surface tension of an aqueous solution of catalyst was measured as a function of catalyst concentration $\left(10 \times 10^{-3}\right.$ to $\left.1.0 \mathrm{mmol} \mathrm{L}^{-1}\right)$ on a Krüss $\mathrm{K} 12$ tensiometer using the Wilhelmy plate method at $25^{\circ} \mathrm{C}$. The surface tension $v s$. catalyst concentration plot gave information on the CMC. Morphologies of the self-assembled aggregates were observed by TEM on a Microscope JEM-2100F at an accelerating voltage of $200 \mathrm{kV}$. Samples were prepared by depositing aqueous solution $\left(0.5 \mathrm{mg} \mathrm{mL}^{-1}\right)$ onto a carboncoated copper grid, followed by removal of excess solution by blotting the grid with filter paper. The samples were dried for $72 \mathrm{~h}$ at room temperature in a desiccator containing dried silica gel. After that, the samples were negatively stained by phosphotungstic acid and dried for another $72 \mathrm{~h}$ before examination. Dynamic light scattering (DLS) was performed using a MS2000 Laser Particle Size Analyzer (Malvern, UK). The sample solutions for measurements were prepared for concentrations of $0.5 \mathrm{mg} \mathrm{mL}^{-1}$ followed by filtering through a $0.45 \mathrm{~lm}$ disposable polyamide (PA) membrane to free it from dust particles. Light transmittance was fixed at $633 \mathrm{~nm}$ with the scattering angle of $90^{\circ}$. The mean diameters of self-assemblies were obtained from the number distribution curves produced by the particle analyzer. The titanium content in samples was determined by inductively coupled plasma mass spectrometry (ICP-MS) on a NexION 300X analyzer (Perkin-Elmer Corp.). Optical rotation of samples was measured in dichloromethane on a WZZ-2A Automatic Polarimeter. The dark-adapted $\mathbf{P N}_{427} \mathbf{A}_{10}-\mathbf{C}$ was obtained by the irradiation of visible light $(\lambda=$ $410 \mathrm{~nm}$ ) for $30 \mathrm{~min}$, and then being kept in the dark for $72 \mathrm{~h}$ to ensure that all the azobenzene chromophores were in transstate.

\section{Preparation of $\mathrm{PN}_{427} \mathrm{~A}_{10}-\mathrm{C}$}

Synthesis of $\mathbf{N}$-azo-acrylamide. Aminoazobenzene (3.0 mmol, $0.592 \mathrm{~g})$, triethylamine $(3.0 \mathrm{mmol}, 0.303 \mathrm{~g}$ ) and benzenediol ( $0.1 \mathrm{mmol}, 0.011 \mathrm{~g}$ ) were dissolved in $10 \mathrm{~mL}$ mixed solvents of acetonitrile and dichloromethane $(1: 1, \mathrm{v} / \mathrm{v})$ at room temperature. Acryloyl chloride ( $4.5 \mathrm{mmol}, 0.410 \mathrm{~g}$ ) in acetonitrile $(5 \mathrm{~mL})$ was then dropwise added into the solution. The mixture was stirred at $55{ }^{\circ} \mathrm{C}$ for $4 \mathrm{~h}$, and the amidation progress was monitored by thin-layer chromatography. After cooling to room temperature, the reaction mixture was filtered through a $0.2 \mu \mathrm{m}$ PTFE filter. The orange residue was washed with water and purified by recrystallization in ethanol to get $\mathrm{N}$-azoacrylamide. FT-IR (KBr): $\gamma_{\max } / \mathrm{cm}^{-1} 3280,3199,3134,3068$, 1670, 1600, 1560. ${ }^{1} \mathrm{H} \mathrm{NMR}\left(\mathrm{CDCl}_{3}, 500 \mathrm{MHz}\right) \delta(\mathrm{ppm}): 7.94-7.89$ 
$(\mathrm{s}, 4 \mathrm{H}, \mathrm{N}=\mathrm{N}-\mathrm{Ph}-H), 7.76(\mathrm{~s}, 2 \mathrm{H}, \mathrm{O}=\mathrm{C}-\mathrm{NH}-\mathrm{Ph}-H), 7.52-7.44(\mathrm{~s}$, $3 \mathrm{H}$, aromatic), 6.50-5.81 (s, 3H, $\mathrm{O}=\mathrm{C}-\mathrm{CH}=\mathrm{CH}$ ).

Synthesis of $\mathbf{P N}_{\mathbf{4 2 7}} \mathbf{A}_{10}$. Monomers of NIPAAm $(24.5 \mathrm{mmol}$, $2.774 \mathrm{~g})$ and $N$-azo-acrylamide $(0.49 \mathrm{mmol}, 0.123 \mathrm{~g})$ were dissolved in THF in a Schlenk tube. AIBN (0.125 mmol, $0.021 \mathrm{~g})$ and 2-aminoethanethiol hydrochloride $(0.25 \mathrm{mmol}, 0.028 \mathrm{~g}$ ) were then added into the solution. The reaction mixture was degassed by bubbling with nitrogen gas at room temperature for $30 \mathrm{~min}$. Polymerization was carried out at $60^{\circ} \mathrm{C}$ for $24 \mathrm{~h}$ with nitrogen protection. After being cooled to room temperature, the mixture was treated with solid $\mathrm{KOH}$ to liberate the terminal amino group. The obtained solution was concentrated under vacuum. Crude product was purified by repeated precipitating from diethyl ether and followed from THF to remove unreacted monomers. After being dried under vacuum for $6 \mathrm{~h}$ at $40^{\circ} \mathrm{C}$, the copolymer of poly(NIPAAm-co-azo) was obtained as yellow powder, which was denoted as $\mathbf{P N}_{\mathbf{4 2 7}} \mathbf{A}_{\mathbf{1 0}}$ (where the repeated units number of NIPAAm and azobenzene in copolymer was 427 and 10, which were determined by ${ }^{1} \mathrm{H}$ NMR spectrum). ${ }^{1} \mathrm{H}$ NMR (500 MHz, DMSO- $\left.d_{6}\right) \delta(\mathrm{ppm}): 7.84(\mathrm{~m}, 40 \mathrm{H},-\mathrm{N}=\mathrm{N}-\mathrm{Ph}-H)$, 7.57-7.56 (m, 20H, O=C-NH-Ph-H), $7.52(\mathrm{~m}, 30 \mathrm{H}, \mathrm{N}=\mathrm{N}-\mathrm{Ph}-$ $H), 7.30-7.19(\mathrm{~m}, 437 \mathrm{H}, \mathrm{O}=\mathrm{C}-\mathrm{N} H-\mathrm{CH}$ and $\mathrm{O}=\mathrm{C}-\mathrm{N} H-\mathrm{Ph}), 3.83$ (m, $427 \mathrm{H}, \mathrm{CH}_{3}-\mathrm{CH}-\mathrm{CH}_{3}$ in NIPAAm), 2.93 (m, 2H, S- $\mathrm{CH}_{2}-\mathrm{CH}_{2}-$ $\left.\mathrm{NH}_{2}\right), 2.63\left(\mathrm{~m}, 2 \mathrm{H}, \mathrm{S}-\mathrm{CH}_{2}-\mathrm{CH}_{2}-\mathrm{NH}_{2}\right), 2.36\left(\mathrm{~m}, 2 \mathrm{H}, \mathrm{S}-\mathrm{CH}_{2}-\mathrm{CH}_{2}-\right.$ $\left.\mathrm{NH}_{2}\right), 1.96\left(\mathrm{~m}, 437 \mathrm{H}, \mathrm{CH}_{2}-\mathrm{CH}-\right.$ in NIPAAm and $\mathrm{N}$-azoacrylamide), $1.44\left(\mathrm{~m}, 874 \mathrm{H},-\mathrm{CH}_{2}-\mathrm{CH}-\right.$ in NIPAAm and $\mathrm{N}$-azoacrylamide), $1.03\left(\mathrm{~s}, 2562 \mathrm{H}, \mathrm{CH}_{3}-\mathrm{CH}-\mathrm{CH}_{3}\right)$. The $M_{\mathrm{n}}$ of $\mathbf{P N}_{427} \mathbf{A}_{10}$ is about $30825 \mathrm{~g} \mathrm{~mol}^{-1}$ based on GPC.

Synthesis of $\mathbf{P N}_{427} \mathbf{A}_{10}-\mathrm{C}$. The obtained $\mathbf{P N}_{427} \mathbf{A}_{10}$ (0.18 $\mathrm{mmol}$, $5.54 \mathrm{~g}), \quad(R, R)-N$-(3,5-di-tert-butylsalicylidene)- $N$-(3-tert-butyl-5chloromethyl-salicylidene)-1,2-cyclohexanediamine $(0.25 \mathrm{mmol}$, $0.137 \mathrm{~g})$ and triethylamine $(0.2 \mathrm{mmol}, 0.02 \mathrm{~g})$ were mixed in dry toluene $(30 \mathrm{~mL})$ under room temperature. The mixture was refluxed for $48 \mathrm{~h}$ under nitrogen protection. After removal of solvent, the residue was dissolved in THF to remove the formed triethylamine hydrochloride through filtration. Filtrate was concentrated in vacuo, and was then treated with $\mathrm{Ti}\left(\mathrm{O}^{\mathrm{i}} \mathrm{Pr}\right)_{4}$ $(0.25 \mathrm{mmol}, 0.07 \mathrm{~g})$ in dichloromethane $(30 \mathrm{~mL})$ for $12 \mathrm{~h}$ at room temperature. The mixture was concentrated under vacuum. Crude product was purified by repeatedly precipitating from tetrahydrofuran using diethyl ether as precipitant. The resulting orange solid was dissolved in chloroform $(20 \mathrm{~mL})$, and treated with water $(2 \mathrm{~mL})$ to remove any traces of $\mathrm{TiO}_{2}$ by filtration. Filtrate was concentrated in vacuum and further dried in vacuum at $40{ }^{\circ} \mathrm{C}$ overnight, giving orange powder of $\mathbf{P N}_{427} \mathbf{A}_{10}$-modified chiral salen $\mathrm{Ti}^{\mathrm{IV}}$ catalyst, denoted as $\mathbf{P N}_{427} \mathbf{A}_{10}$-C. ${ }^{1} \mathrm{H}$ NMR (500 MHz, DMSO- $\left.d_{6}\right) \delta(\mathrm{ppm}): \delta 9.97(\mathrm{~s}, 2 \mathrm{H}$, $\mathrm{Ph}-H \mathrm{C}=\mathrm{N}-)$, 7.90 (s, 2H, Ph- $H$ in Ti(salen)), $7.84(\mathrm{~m}, 42 \mathrm{H},-\mathrm{N}=$ $\mathrm{N}-\mathrm{Ph}-H), 7.60-7.56(\mathrm{~m}, 20 \mathrm{H}, \mathrm{O}=\mathrm{C}-\mathrm{NH}-\mathrm{Ph}-H), 7.52(\mathrm{~m}, 30 \mathrm{H}$, $\mathrm{N}=\mathrm{N}-\mathrm{Ph}-\mathrm{H}), 7.29-7.20(\mathrm{~m}, 437 \mathrm{H}, \mathrm{O}=\mathrm{C}-\mathrm{N} H-\mathrm{CH}$ and $\mathrm{O}=\mathrm{C}-$ $\mathrm{NH}-\mathrm{Ph}), 3.83\left(\mathrm{~m}, 427 \mathrm{H}, \mathrm{CH}_{3}-\mathrm{CH}-\mathrm{CH}_{3}\right.$ in NIPAAm), 3.17-3.16 (m, 2H, cyclohexyl- $H$ ), 2.92-2.90 (m, 2H, NH-CH$-\mathrm{Ti}($ salen)), $2.63\left(\mathrm{~m}, 2 \mathrm{H}, \mathrm{S}-\mathrm{CH}_{2}-\mathrm{CH}_{2}-\mathrm{NH}\right), 2.36\left(\mathrm{~m}, 2 \mathrm{H}, \mathrm{S}-\mathrm{CH}_{2}-\mathrm{CH}_{2}-\mathrm{NH}\right)$, $2.17\left(\mathrm{~m}, 2 \mathrm{H}, \mathrm{CH}_{3}-\mathrm{CH}-\mathrm{CH}_{3}\right.$ of ${ }^{\mathrm{i}} \mathrm{PrO}-$ in $\mathrm{Ti}($ salen$\left.)\right), 1.95(\mathrm{~m}, 437 \mathrm{H}$, $\mathrm{CH}_{2}-\mathrm{CH}-$ in NIPAAm and $\mathrm{N}$-azo-acrylamide), $1.44(\mathrm{~s}, 874 \mathrm{H}$, $-\mathrm{CH}_{2}-\mathrm{CH}-$ in NIPAAm and $\mathrm{N}$-azo-acrylamide), $1.22(\mathrm{~m}, 8 \mathrm{H}$, cyclohexyl- $H$ ), 1.17 (m, 39H, $-\mathrm{CH}_{3}$ of $t$-Bu and ${ }^{\mathrm{i}} \mathrm{PrO}$ - in Ti(salen)), $1.03\left(\mathrm{~s}, 2562 \mathrm{H}, \mathrm{CH}_{3}-\mathrm{CH}-\mathrm{CH}_{3}\right) \cdot[\alpha]_{\mathrm{D}}^{20}=-16.0\left(\mathrm{C}=0.005 \mathrm{~g} \mathrm{~mL} \mathrm{~m}^{-1}\right.$ in $\mathrm{CH}_{2} \mathrm{Cl}_{2}$ ). Titanium content: $0.018 \mathrm{mmol} \mathrm{g}^{-1}$. The LCST of $\mathbf{P N}_{\mathbf{4 2 7}} \mathbf{A}_{10}-\mathbf{C}$ is $26^{\circ} \mathrm{C}$ based on transmittance measurement.

\section{Catalyst testing}

Before reaction, $\mathbf{P N}_{\mathbf{4 2 7}} \mathbf{A}_{\mathbf{1 0}}-\mathbf{C}$ was irradiated by visible light $(\lambda=$ $410 \mathrm{~nm}$ ) for $30 \mathrm{~min}$, and then kept in the dark for $72 \mathrm{~h}$ to ensure that all the azobenzene chromophores were in trans-state. The dark-adapted $\mathbf{P N}_{\mathbf{4 2 7}} \mathbf{A}_{\mathbf{1 0}}$-C (0.1 mol\% substrate, based on the titanium content in catalyst) and methyl aryl sulfides (1.0 mmol) were added to $\mathrm{H}_{2} \mathrm{O}(2 \mathrm{~mL})$ under stirring at $25{ }^{\circ} \mathrm{C}$. The mixture was exposed to UV light $(\lambda=365 \mathrm{~nm})$ for a certain time, and then wrapped with aluminum foil. $\mathrm{H}_{2} \mathrm{O}_{2}(30 \mathrm{wt} \%$, $1.2 \mathrm{mmol}$ ) was dropwise added into the solution within $15 \mathrm{~min}$. The resulting mixture was stirred at room temperature until the reaction was judged to be complete based on GC analysis. Then, the reaction mixture was heated to $32{ }^{\circ} \mathrm{C}$. Catalyst was precipitated out from the reaction system completely, washed with diethyl ether $(3 \times 5 \mathrm{~mL})$, dried in a vacuum, and finally recharged with fresh substrate and oxidant for the next catalytic cycle. The supernatants separated from reaction system were extracted with dichloromethane thrice. Combined organic phase was concentrated in vacuum. Further purification of the residue by chromatography on silica gel (petroleum ether/ethyl acetate, 1.5/1) afforded pure chiral sulfoxides. The products have been identified by ${ }^{1} \mathrm{H}$ NMR and ${ }^{13} \mathrm{C}$ NMR spectra. The conversion and chemoselectivity of chiral sulfoxides were measured by a $6890 \mathrm{~N}$ gas chromatograph (Agilent Co.) equipped with a capillary column (HP19091G-B213, $30 \mathrm{~m} \times 0.32 \mathrm{~mm}$ $\times 0.25 \mu \mathrm{m})$ and a FID detector. Ee values of corresponding chiral sulfoxides were determined by HPLC analysis using the Daicel Chiralpak AD columns. Detailed NMR spectra and HPLC analysis for the chiral sulfoxides were available in ESI. $\dagger$

Methyl phenyl sulfoxide. Chemoselectivity: 99\% determined by GC, nitrogen was used as the carrier gas with a flow of $30 \mathrm{~mL} \mathrm{~min}{ }^{-1}$, the injector temperature and the detector temperature were $250{ }^{\circ} \mathrm{C}$, the column temperature was programmed from 80 to $180{ }^{\circ} \mathrm{C}$ with $6{ }^{\circ} \mathrm{C} \mathrm{min}^{-1}, t_{\text {methyl phenyl sulfoxide }}=$ $6.9 \mathrm{~min}$; ee value: $99 \%$ determined by $\mathrm{HPLC}(\mathrm{i}-\mathrm{PrOH} / n$-hexane $=$ $5: 5(\mathrm{v} / \mathrm{v}))$; flow rate $=1.0 \mathrm{~mL} \min ^{-1} ; 25{ }^{\circ} \mathrm{C} ; \lambda=254 \mathrm{~nm}$; major enantiomer $t_{\mathrm{R}}=4.4 \mathrm{~min}$, minor enantiomer $t_{\mathrm{S}}=5.2 \mathrm{~min} ;{ }^{1} \mathrm{H}$ $\mathrm{NMR}\left(\mathrm{CDCl}_{3}, 500 \mathrm{MHz}\right) \delta(\mathrm{ppm}): 2.49$ (s, 3H, Me), 7.27-7.29 (m, $3 \mathrm{H}, \mathrm{ArH}), 7.42-7.44(\mathrm{~m}, 2 \mathrm{H}, \mathrm{ArH}) ;{ }^{13} \mathrm{C} \mathrm{NMR}\left(\mathrm{CDCl}_{3}, 125 \mathrm{MHz}\right)$ $\delta$ (ppm): $43.1\left(\mathrm{SCH}_{3}\right), 122.8,128.6,130.3,144.9(\mathrm{ArC})$.

Ethyl phenyl sulfoxide. Chemoselectivity: 91\% determined by GC, nitrogen was used as the carrier gas with a flow of $30 \mathrm{~mL} \mathrm{~min}^{-1}$, the injector temperature and the detector temperature were $250{ }^{\circ} \mathrm{C}$, the column temperature was $180^{\circ} \mathrm{C}$, $t_{\text {ethyl phenyl sulfoxide }}=2.5 \mathrm{~min}$; ee value: $97 \%$, determined by HPLC (i-PrOH $/ n$-hexane $=2: 8(\mathrm{v} / \mathrm{v}))$; flow rate $=1.0 \mathrm{~mL} \mathrm{~min}^{-1}$; $25{ }^{\circ} \mathrm{C} ; \lambda=254 \mathrm{~nm}$; major enantiomer $t_{\mathrm{R}}=6.4 \mathrm{~min}$ and minor enantiomer $t_{\mathrm{S}}=8.2 \mathrm{~min} ;{ }^{1} \mathrm{H} \mathrm{NMR}\left(\mathrm{CDCl}_{3}, 500 \mathrm{MHz}\right) \delta(\mathrm{ppm})$ : 7.59-7.53 (m, 2H, $\operatorname{Ar} H$ ), 7.52-7.47 (m, 3H, $\operatorname{Ar} H)$, 2.92-2.72 (m, $\left.2 \mathrm{H},-\mathrm{CH}_{2}-\right), 1.19-1.16(\mathrm{~m}, 3 \mathrm{H}, \mathrm{Me}) ;{ }^{13} \mathrm{C} \mathrm{NMR}\left(\mathrm{CDCl}_{3}, 125 \mathrm{MHz}\right)$ $\delta$ (ppm): $5.91\left(\mathrm{CH}_{3}\right), 50.24\left(\mathrm{SCH}_{2}\right), 124.13,129.09,130.88,143.25$ $(\operatorname{ArC})$. 
Methyl $\boldsymbol{p}$-methoxyphenyl sulfoxide. Chemoselectivity: $92 \%$ determined by GC, nitrogen was used as the carrier gas with

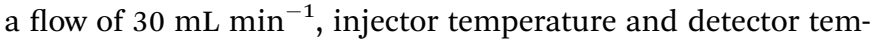
perature were $250{ }^{\circ} \mathrm{C}$, the column temperature was programmed from 80 to $180{ }^{\circ} \mathrm{C}$ with $6{ }^{\circ} \mathrm{C} \mathrm{min}^{-1}$, $t_{\text {methyl } p \text {-methoxyphenyl sulfoxide }}=11.7 \mathrm{~min}$; ee value: $97 \%$, determined by HPLC $\left({ }^{\mathrm{i}} \mathrm{PrOH} / n\right.$-hexane $\left.=4: 6(\mathrm{v} / \mathrm{v})\right)$; flow rate $=$ $1.0 \mathrm{~mL} \mathrm{~min}{ }^{-1} ; 25{ }^{\circ} \mathrm{C} ; \lambda=254 \mathrm{~nm}$; major enantiomer $t_{\mathrm{R}}=$ $5.5 \mathrm{~min}$ and minor enantiomer $t_{\mathrm{S}}=6.6 \mathrm{~min} ;{ }^{1} \mathrm{H} \mathrm{NMR}\left(\mathrm{CDCl}_{3}\right.$, $500 \mathrm{MHz}) \delta(\mathrm{ppm}): 7.60-7.57(\mathrm{~d}, 2 \mathrm{H}, \mathrm{ArH}), 7.03-7.01(\mathrm{~d}, 2 \mathrm{H}$, $\mathrm{ArH}), 3.84$ (s, 3H, $\left.\mathrm{OCH}_{3}\right), 2.69\left(\mathrm{~s}, 3 \mathrm{H}, \mathrm{SCH}_{3}\right) ;{ }^{13} \mathrm{C} \mathrm{NMR}\left(\mathrm{CDCl}_{3}\right.$, $125 \mathrm{MHz}) \delta(\mathrm{ppm}): 43.9\left(\mathrm{SCH}_{3}\right), 55.5\left(\mathrm{OCH}_{3}\right), 114.8,125.4,136.6$, $162.0(\mathrm{ArC})$.

Methyl o-methoxyphenyl sulfoxide. Chemoselectivity: 99\% nitrogen was used as the carrier gas with a flow of $30 \mathrm{~mL} \mathrm{~min}{ }^{-1}$, injector temperature and detector temperature were $250{ }^{\circ} \mathrm{C}$, the column temperature was $180{ }^{\circ} \mathrm{C}, t_{\text {methyl } o \text {-methoxyphenyl sulfoxide }}=$ $9.8 \mathrm{~min}$; ee value: $99 \%$ determined by HPLC $(\mathrm{i}-\mathrm{PrOH} / n$-hexane $=$ $5: 5(\mathrm{v} / \mathrm{v}))$; flow rate $=1.0 \mathrm{~mL} \min ^{-1} ; 25{ }^{\circ} \mathrm{C} ; \lambda=254 \mathrm{~nm}$; major enantiomer $t_{\mathrm{R}}=4.8 \mathrm{~min}$ and minor enantiomer $t_{\mathrm{S}}=5.7 \mathrm{~min} ;{ }^{1} \mathrm{H}$ NMR $\left(\mathrm{CDCl}_{3}, 500 \mathrm{MHz}\right) \delta(\mathrm{ppm}): 7.82-7.80$ (m, 1H, $\left.\mathrm{ArH}\right), 7.46-$ $7.42(\mathrm{~m}, 1 \mathrm{H}, \operatorname{Ar} H), 7.19-7.16(\mathrm{~m}, 1 \mathrm{H}, \operatorname{Ar} H), 6.92-6.90(\mathrm{~m}, 1 \mathrm{H}$, $\mathrm{Ar} H$ ), 3.87 (s, 3H, OCH $\left.H_{3}\right), 2.76\left(\mathrm{~s}, 3 \mathrm{H}, \mathrm{SCH}_{3}\right) ;{ }^{13} \mathrm{C} \mathrm{NMR}\left(\mathrm{CDCl}_{3}\right.$, $125 \mathrm{MHz}) \delta(\mathrm{ppm}): 41.16\left(\mathrm{SCH}_{3}\right), 55.64\left(\mathrm{OCH}_{3}\right), 110.53,121.65$, 124.58, 131.89, 133.07, 154.76 (ArC).

\section{Sulfoxidation reaction for kinetic measurement}

Chiral salen $\mathrm{Ti}^{\mathrm{IV}}$ catalyst $(0.1 \mathrm{~mol} \%$ of substrate, based on titanium ion content) was stirred with methyl phenyl sulfides $(1.0 \mathrm{mmol})$ in solvent $(2 \mathrm{~mL})$ at $25{ }^{\circ} \mathrm{C} . \mathrm{H}_{2} \mathrm{O}_{2}(30 \mathrm{wt} \%, 1.2 \mathrm{mmol})$ was then added into the stirred solution in one portion. To determine the rate of sulfoxidation, aliquots at an interval of 10 min were drawn from the reaction mixture, filtrated through silica gel with ethyl acetate as an eluent and analyzed by GC.

\section{Conflicts of interest}

There are no conflicts to declare.

\section{Acknowledgements}

This work was supported by the National Natural Science Foundation of China (21676078, 21476069), the Natural Science Foundation of Hunan Province for Distinguished Young Scholar (2016JJ1013), the Program for Excellent Talents in Hunan Normal University (ET14103), and Hunan Provincial Innovation Foundation For Postgraduate (CX2016B168).

\section{References}

1 (a) L. Marchetti and M. Levine, ACS Catal., 2011, 1, 1090; (b) S. Mura, J. Nicolas and P. Couvreur, Nat. Mater., 2013, 12, 991; (c) Y. Zhao, F. Sakai, L. Su, Y. Liu, K. Wei, G. Chen and M. Jiang, Adv. Mater., 2013, 25, 5215; (d) Y. Liu, X. Ma, J. Xie, P. Liu, B. Dai and R. He, Appl. Organomet. Chem., 2013, 27, 494; (e) A. Doring, W. Birnbaum and D. Kuckling,
Chem. Soc. Rev., 2013, 42, 7391; (f) Y. Liu, T. Pauloehrl, S. I. Presolski, L. Albertazzi, A. R. A. Palmans and E. W. Meijer, J. Am. Chem. Soc., 2015, 137, 13096; $(g)$ A. F. Cardozo, C. Julcour, L. Barthe, J. F. Blanco, S. Chen, F. Gayet and F. D'agosto, J. Catal., 2015, 324, 1.

2 (a) B. M. Neilson and C. W. Bielawski, ACS Catal., 2013, 3, 1874; (b) X. Mao, W. Tian, J. Wu, G. C. Rutledge and T. A. Hatton, J. Am. Chem. Soc., 2015, 137, 1348.

3 (a) X. He, M. Aizenberg, O. Kuksenok, L. D. Zarzar, A. Shastri, A. C. Balazs and J. Aizenberg, Nature, 2012, 487, 214; (b) W. Li, L. Huang, X. Ying, Y. Jian, Y. Hong, F. Hu and Y. Du, Angew. Chem., Int. Ed., 2015, 54, 3126; (c) Y. Zhang, R. Tan, G. Zhao, X. Luo, C. Xing and D. Yin, J. Catal., 2016, 335, 62; (d) W. C. de Vries, D. Grill, M. Tesch, A. Ricker, H. Nüsse, J. Klingauf, A. Studer, V. Gerke and B. J. Ravoo, Angew. Chem., Int. Ed., 2017, 56, 9603; (e) Y. Zhou, Y. Chen, P. Zhu, W. Si, J. Hou and Y. Liu, Chem. Commun., 2017, 53, 3681.

4 (a) S. Yagai, T. Karatsu and A. Kitamura, Chem.-Eur. J., 2005, 11, 4054; (b) Y. Wang, H. Xu and X. Zhang, Adv. Mater., 2009, 21, 2849; (c) G. Shen, G. Xue, J. Cai, G. Zou, Y. Li and Q. Zhang, Soft Matter, 2013, 9, 2512.

5 (a) T. Imahori, R. Yamaguchi and S. Kurihara, Chem.-Eur. J., 2012, 18, 10802; (b) A. Parrot, G. Izzet, L. Chamoreau, A. Proust, O. Oms, A. Dolbecq, K. Hakouk, H. E. Bekkachi, P. Deniard, R. Dessapt and P. Mialane, Inorg. Chem., 2013, 52, 11156; (c) Y. Shiraishi, K. Tanaka and T. Hirai, ACS Appl. Mater. Interfaces, 2013, 5, 3456; (d) Z. Chen, L. Zhou, W. Bing, Z. Zhang, Z. Li, J. Ren and X. Qu, J. Am. Chem. Soc., 2014, 136, 7498; (e) A. Wu, F. Lu, P. Sun, X. Gao, L. Shi and L. Zheng, Langmuir, 2016, 32, 8163; $(f)$ M. Karimi, P. S. Zangabad, S. Baghaee-Ravari, M. Ghazadeh, H. Mirshekari and M. R. Hamblin, J. Am. Chem. Soc., 2017, 139, 4584.

6 (a) L. Zhu, H. Yan, C. Y. Ang, K. T. Nguyen, M. Li and Y. Zhao, Chem.-Eur. J., 2012, 18, 13979; (b) T. Tian, Y. Song, J. Wang, B. Fu, Z. He, X. Xu, A. Li, X. Zhou, S. Wang and X. Zhou, J. Am. Chem. Soc. , 2016, 138, 955; (c) Y. Guo, Y. Gong, Y. Gao, J. Xiao, T. Wang and L. Yu, Langmuir, 2016, 32, 9293; (d) A. H. Gelebart, D. J. Mulder, M. Varga, A. Konya, G. Vantomme, E. W. Meijer, R. L. B. Selinger and D. J. Broer, Nature, 2017, 546, 632; (e) Y. Sun, J. Ma, F. Zhang, F. Zhu, Y. Mei, L. Liu, D. Tian and H. Li, Nat. Commun., 2017, 8, 260; (f) H. Zhou, C. Xue, P. Weis, Y. Suzuki, S. Huang, K. Koynov, G. K. Auernhammer, R. Berger, H. Butt and S. Wu, Nat. Chem., 2017, 9, 145.

7 T. Sun, G. Qing, B. Su and L. Jiang, Chem. Soc. Rev., 2011, 40, 2909.

8 J. E. Chung, M. Yokoyama, T. Aoyagi, Y. Sakurai and T. Okano, J. Controlled Release, 1998, 53, 119.

9 M. Holbach, X. Zheng, C. Burd, C. W. Jones and M. Weck, J. Org. Chem., 2006, 71, 2903.

10 C. Lv, D. Xu, S. Wang, C. Miao, C. Xia and W. Sun, Catal. Commun., 2011, 12, 1242.

11 T. Sun and G. Qing, Adv. Mater., 2011, 23, 57.

12 K. Han, W. Su, M. Zhong, Q. Yan, Y. Luo, Q. Zhang and Y. Li, Macromol. Rapid Commun., 2008, 29, 1866. 
13 (a) B. Yu, X. Jiang, R. Wang and J. Yin, Macromolecules, 2010, 43, 10457; (b) J. Hu, H. Yu, L. H. Gan and X. Hu, Soft Matter, 2011, 7, 11345; (c) M. Baroncini, S. d'Agostino, G. Bergamini, P. Ceroni, A. Comotti, P. Sozzani, I. Bassanetti, F. Grepioni, T. M. Hernandez, S. Silvi, M. Venturi and A. Credi, Nat. Chem., 2015, 7, 234; (d) S. R. Deka, S. Yadav, M. Mahato and A. K. Sharma, Colloids Surf., B, 2015, 135, 150.

14 G. Markiewicz, D. Pakulski, A. Galanti, V. Patroniak, A. Ciesielski, A. R. Stefankiewicz and P. Samori, Chem. Commun., 2017, 53, 7178.

15 J. Rao and A. Khan, J. Am. Chem. Soc., 2013, 135, 14056.

16 M. T. Garcia, I. Ribosa, L. Perez, A. Manresa and F. Comelles, Colloids Surf., B, 2014, 123, 318.

17 H. Shaikh, M. Hassan and N. M. Ahmad, Phot. Nano. Fund. Appl, 2014, 12, 34.

18 (a) J. Y. Lee and M. Schic, Biophys. J., 1994, 5, 1699; (b) M. Müller, K. Katsov and M. Schick, Biophys. J., 2003, 85, 1611.
19 L. Lin, Z. Yan, J. Gu, Y. Zhang, Z. Feng and Y. Yu, Macromol. Rapid Commun., 2009, 30, 1089.

20 (a) Y. N. Belokon, M. North, V. I. Maleev, N. V. Voskoboev, M. A. Moskalenko, A. S. Peregudov, A. V. Dmitriev, N. S. Ikonnikov and H. B. Kagan, Angew. Chem., Int. Ed., 2004, 43, 4085; (b) M. Li, S. Qi, Y. Jin, W. Yao, S. Zhang and J. Zhao, Colloids Surf., B, 2014, 123, 852.

21 A. Lu and R. K. O'Reilly, Curr. Opin. Biotechnol., 2013, 24, 639. 22 Y. Zhang, R. Tan, M. Gao, P. Hao and D. Yin, Green Chem., 2017, 19, 1182.

23 J. Li, Y. Tang, Q. Wang, X. Li, L. Cun, X. Zhang, J. Zhu, L. Li and J. Deng, J. Am. Chem. Soc., 2012, 134, 18522.

24 T. Dwars, E. Paetzold and G. Oehme, Angew. Chem., Int. Ed., 2005, 44, 7174.

25 C. Baleizão and H. Garcia, Chem. Rev., 2006, 106, 3987. 